\title{
Em Busca da Estabilidade Perdida: explorando alguns limites para o ordenamento das finanças internacionais
}

\author{
Autor $^{1}$
}

Resumo: As evidências predominantes sugerem que a liberalização financeira não está associada com o crescimento econômico. Pelo contrário, assim-chamada globalização financeira ampliou a volatilidade macroeconômica. Apesar disso, houve um recuo na implementação de reformas na "arquitetura financeira internacional". Esse trabalho analisa alguns limites na agenda de reformas. Argumenta-se que, aparentemente, não há espaço para uma "agenda ampliada" que incorpore temas não-convencionais, como os mecanismos estatutários para a resolução de problemas de endividamento.

\section{Introdução}

Existe hoje um razoável distanciamento histórico acerca dos fenômenos que vem marcando a assim-chamada globalização, termo síntese para o processo de maior integração, no plano internacional, de várias esferas da vida econômica, política e social, associada a uma aceleração das tecnologias de informação e à redefinição dos espaços de atuação do "Estado" e dos "Mercados" (Bacha, 2002). A crescente lacuna entre as promessas de desenvolvimento e democracia, e a realidade de exclusão e congelamento (muitas vezes com retrocesso) da rígida hierarquia que marca a divisão internacional do trabalho entre as economias capitalistas, fez crescer a insatisfação da comunidade global com os resultados da globalização (CEPAL, 2002, Stiglitz, 2002, Ocampo, 2003, World Bank, 2001). O momento é de reflexão e questionamento.

Em uma perspectiva de longo prazo, pode-se verificar que a economia internacional já atravessou diversos ciclos de integração. Nos períodos de disseminação de novas tecnologias com redução de custos de transação, onde o ambiente político e econômico era marcado por uma relativa estabilidade, verificou-se um sensível avanço na integração mundial. A hegemonia britânica do final do século XIX, início do século XX, e a Pax norte-americana do regime de Bretton Woods, são exemplos neste sentido. Por outro lado, a instabilidade econômica e social do entre guerras, a crise da dívida dos países em desenvolvimento nos anos 1980 e o período que se inaugura na segunda metade da década de 1990, são os contra-exemplos. Explicitam-se as fragilidades institucionais que ordenam as relações internacionais e, que, por isso mesmo, mostram-se incapazes de fazer frente à instabilidade gerada nos mercados (Bordo et. al, 2001, Eichengreen, 1996, World Bank, 2000 e 2001).

Este trabalho enfatiza a dimensão financeira do processo recente de divergência entre o desenvolvimento dos mercados e a base institucional subjacente capaz de lhe dar suporte. Somam-se as evidências de que não há uma ligação incondicional entre a liberalização financeira e a promoção do crescimento da renda. Além disso, as diversas tentativas de se criar um ambiente propício ao retorno dos capitais privados aos países em desenvolvimento têm se mostrado insuficientes. Reaparece, sob nova roupagem, a velha tensão entre a criação de instituições globais capazes de regular a maior instabilidade potencial associada aos fluxos financeiros, e os interesses políticos e de atores privados dos países centrais, que emanam, principalmente, do circuito Wall Street - Washington.

Além dessa introdução, os argumentos estão organizados em mais quatro secções: (i) inicia-se com uma revisão das evidências empíricas mais recentes acerca da capacidade dos fluxos financeiros desregulados gerarem crescimento com estabilidade nos países em desenvolvimento; (ii) a seguir são resgatados alguns argumentos teóricos que reforçam a noção de que é necessária a cosntituiçãod e anteparos institucionais capazes de estabilizar os mercados financeiros; (iii) para, então, explorar-se a

\footnotetext{
${ }^{1}$ Nome: . Filiação institucional: .E-mail: . . Versão: julho de 2003. Todas as traduções de citações foram feitas pelo autor.
} 
agenda da discussão recente em torno das reformas capazes de ordenar as finanças globais; (iv) seguem algumas considerações finais.

\section{Liberalização Financeira e Crescimento com Estabilidade}

Em uma retrospectiva histórica, o Banco Mundial constatou recentemente que “... (as) ondas de capitais para os mercados emergentes têm sido, tipicamente, parte de um longo, periódico e rápido processo de expansão da economia global. Elas ocorrem quando uma ampla difusão de mudanças tecnológicas aprimora as comunicações e transportes, o crescimento é animador, o comércio mundial está em expansão, as inovações financeiras são rápidas, e o clima político lhes dão sustentabilidade." (World Bank, 2000:119, grifos no original). Todavia, segue a análise, "(todos) os episódios passados de expansão dos fluxos de capitais para os mercados emergentes terminaram em severas crises internacionais. Hard landings mais do que soft landings têm sido a regra (...) Booms nos fluxos privados de capitais têm sido pontuados por freqüentes crises bancárias e cambiais nos países receptores, e terminado, usualmente, em severas rupturas econômicas e conflitos políticos". (idem, grifos no original).

Com tais observações, o Banco Mundial não estava sugerindo a existência de uma trajetória determinística para os movimentos de "sístole" e "diástole" nas finanças internacionais, senão alertando para a necessidade de se desenvolver bases institucionais mais sólidas, capazes de minimizar os riscos associados à instabilidade intrínseca dos mercados financeiros. E mais, que tal instabilidade tenderia a comprometer a integração comercial global e a paz social doméstica e internacional (World Bank, 2002). Esta mesma perspectiva esteve presente nos líderes políticos internacionais que arquitetaram o Sistema de Bretton Woods, centrado na criação de um regime de câmbio fixo porém ajustável, com o dólar norte-americano desempenhando o papel de divisa-chave, e na existência de duas instituições financeiras multilaterais, o FMI e o Banco Mundial, responsáveis, respectivamente, para dar suporte financeiro a países com dificuldades em manter a conversibilidade da conta corrente, e financiar a reconstrução da Europa e a industrialização da periferia capitalista.

É sempre interessante lembrar as tensões que marcaram as propostas norte-americana e inglesa de ordenamento da economia internacional no pós-guerra. Keynes propunha a replicação, no plano internacional, de um modelo de Banco Central (Clearing Union) capaz de emitir e gerir uma moeda internacional (bancor), com vistas a reduzir os impactos potenciais de crises de liquidez comprometedoras do livre-comércio, e melhor distribuir (entre credores e devedores) o ônus do ajuste das dificuldades dos balanços de pagamentos. O Tesouro dos EUA defendeu um modelo reduzido, na qual o Banco Central Internacional de Keynes transformou-se em uma modesta "cooperativa de crédito", o FMI. Aparentemente, os EUA não estavam dispostos a abrir mão de sua autonomia decisória em nome de um arranjo burocrático global, por mais atraente que fosse a racionalidade associada à idéia de um efetivo "prestamista em última instância" atuando na esfera internacional (Keynes, 1943, 1944, Davidson, 1992, Ferrari Filho, 1999). Anos mais tarde, Triffin (1960) alertou, mais uma vez, para a instabilidade genética criada em Bretton Woods, onde o sucesso do dólar como divisa-chave traria, mais cedo ou mais tarde, o dilema entre a preservação da paridade dólar-ouro e as necessidades domésticas de manutenção de políticas expansionistas nos EUA. Diante de tal tensão, e com uma base institucional frágil na ausência de uma instituição internacional provida de mandato e instrumentos capazes de regular a liquidez, o regime cambial centrado no padrão dólar-ouro estaria fadado a sucumbir (Eichengreen, 1996).

As crises especulativas que marcaram os anos 1960, estavam associadas ao próprio sucesso do acordo de Bretton Woods em garantir condições favoráveis ao ordenamento da economia internacional. Findo o período de forte "escassez de dólares", com o crescimento da renda e do comércio dos 
principais países europeus, a conversibilidade cambial para as transações em conta corrente e a paulatina redução das restrições à mobilidade de capitais, gerou-se um ambiente propício para que os especuladores testassem os limites do compromisso dos governos nacionais com a paridade cambial. A válvula de escape dos Atos Constitutivos do FMI, que previa a possibilidade de ajustes na taxa de câmbio quando da ocorrência de "desequilíbrios fundamentais" era a senha para o ataque. Muitos países europeus estavam com suas moedas desalinhadas com respeito aos fundamentos econômicos. Imaginava-se que com o abandono do regime de câmbio fixo, poder-se-ia chegar de forma natural ao pleno emprego com estabilidade no balanço de pagamentos. As crises cambiais ficariam no passado (Eichengreen, 1996, Bordo \& Eichengreen, 2002).

Todavia, o período que se seguiu à ruptura do Sistema de Bretton Woods não deixou de conhecer seus episódios de crises recorrentes ${ }^{2}$. Em especial, nas décadas de 1980 e 1990, a liberalização financeira esteve no epicentro das crises. Dentre as regularidades empíricas que marcaram tais episódios, a literatura têm destacado a expansão do crédito doméstico associada à liberalização financeira (interna e externa), que estão na origem dos booms nos mercados reais e financeiros. Somam-se a apreciação da taxa de câmbio, a fragilização externa, com a deterioração dos saldos em conta corrente, e redução na liquidez (ampliação da relação entre passivos e ativos externos e encurtamento das posições passivas); dentre outros fatores (Kaminsky et. al., 1998, Demirgüç-kunt \& Detragiache, 1998, IMF 1998, Aziz et. al., 2000).

Depois do boom de afluxo de capitais privados para os mercados emergentes, entre a segunda metade dos anos 1980 e meados da década de 1990, a crise asiática (1997-1998) inaugurou uma fase de retração daqueles ${ }^{3}$. O que poderia ser um episódio isolado, mostrou-se como um evento definidor de um novo momento. Depois da crise asiática o mundo foi abalado pela crise russa e a falência de um importante fundo hedge norte-americano - o Long Term Capital Management -, em 1998, a crise cambial brasileira de 1999, e as crises da Argentina e Turquia (2000-2002), além de uma série de episódios de menor visibilidade fora dos meios especializados, com destaque para a crise no pagamento dos Brady bonds do Equador, a instabilidade na Ucrânia, Paquistão e Venezuela, entre outros. Tais eventos deram margem a questionamentos sobre a capacidade dos arranjos institucionais vigentes em dar suporte ao processo de globalização, especialmente em sua dimensão financeira, ponto a ser destacado na seqüência desse trabalho.

Com a retração na entrada autônoma de capitais privados nos países em desenvolvimento, o aumento da instabilidade financeira, expresso em recorrentes crises, e o crescente questionamento sobre os pretensos vínculos automáticos entre liberalização da conta capital e crescimento, o establishment oficial passou a demonstrar uma maior cautela na exposição dos custos e benefícios da liberalização financeira (Fendt \& Lins, 2002, Ocampo, 2003, Cunha \& Prates, 2003) ${ }^{4}$. Em dos mais

\footnotetext{
${ }^{2}$ O FMI (1998) identificou, para o período 1975-97, 158 episódios de crises cambiais e 54 de crises bancárias, que atingiram com mais freqüência os países em desenvolvimento, mas que não pouparam as economias centrais. Com uma amostra de 22 países industrializados e 31 países em desenvolvimento (EUA e Alemanha foram excluídos) verificou-se que, nos casos mais graves, os custos fiscais associados às crises oscilaram entre $30 \%$ e $40 \%$ do PIB. A perda de renda, calculada pela diferença entre a linha de tendência do produto e seu resultado após a crise, foi em média de $4,25 \%$ (sendo maior nos países em desenvolvimento). As crises cambiais foram identificadas pela construção de um índice de pressões nos mercados cambiais, que leva em conta as mudanças nas taxas de câmbio e as perdas de reserva e/ou aumento dos juros para amortizar os ataques especulativos; e as crises bancárias por eventos ex-post como fechamento, estatização e/ou fusões forçadas de instituições, corridas bancárias ou elevados pacotes de auxílio de liquidez pelo governo.

${ }^{3}$ A entrada líquida de capital privado nos países em desenvolvimento atingiu seu auge em 1996, com US\$ 233 bilhões. Com a crescente instabilidade internacional, aquele montante atingiu seu menor valor absoluto desde a crise da dívida dos anos 1980: US\$ 8,9 bilhões em 2000. Esta queda deve ser atribuída à forte retração nos créditos bancários e nos fluxos de investimentos em portfólio, muito mais voláteis do que o investimento direto externo (IDE). Em termos relativos, o ano de 1996 marcou o pico da entrada líquida de capitais nos emergentes: 3,5\% do PIB conjunto destes países. A partir da crise asiática, este indicador caiu para níveis tão baixos quanto os verificados no período da crise da dívida dos anos 1980. Cálculos do autor a partir da base de dados do FMI (www.imf.org) - World Economic Outlook, outubro de 2001.

${ }^{4}$ No final dos anos 1980, início dos anos 1990, vigorou um grande otimismo acerca da globalização financeira, postura reforçada pela pressão norte-americana em torno da abertura da conta capital em vários países em desenvolvimento. $\mathrm{O}$ alerta de experts acadêmicos
} 
recentes estudos sistemáticos sobre esse tema, o $\mathrm{FMI}^{5}$ procurou mensurar os impactos dos fluxos de capitais no crescimento. Partiu-se da tentativa de mensurar a liberalização, a partir de duas proxys: (i) uma media de caráter qualitativo, baseada na existência ou não de regras restritivas à livre mobilidade de capitais, nos termos reportados pelo "Relatório Anual de Arranjos e Restrições Cambiais", do próprio Fundo; e (ii) uma segunda medida, quantitativa, dada pela soma dos estoques de ativos e passivos financeiros sobre o PIB, em uma analogia ao indicador de abertura comercial (exportações mais importações sobre o PIB). Neste sentido, um país qualitativamente "fechado", por apresentar restrições à livre mobilidade de capitais pode ser "aberto" pelo indicador quantitativo, como no caso da China.

Regredindo essas proxys contra diversos indicadores de desenvolvimento econômico e financeiro, o Fundo constatou um balanço nada conclusivo sobre as virtudes da liberalização financeira. No plano real, verificou-se a existência de uma “... fraca relação entre crescimento e liberalização da conta capital e, como em outros estudos, tem dificuldade de encontrar relações significativas [entre crescimento e liberalização].”(IMF, 2001:143). Por outro lado, identificou-se um efeito positivo sobre os investimentos e o desenvolvimento do setor financeiro. Os resultados do Fundo também apontaram para a existência de custos não desprezíveis associados à liberalização, em termos de aumento da instabilidade. A ampliação da liberalização da conta capital em muitos países em desenvolvimento teria vindo acompanhada de aumento na volatilidade dos fluxos líquidos de capital e redução no crescimento econômico ${ }^{6}$. Buscou-se a explicação para a fraca ligação entre crescimento e liberalização financeira nas falhas institucionais dos países receptores de capital. Quanto mais frágeis as instituições domésticas, especialmente de regulação dos mercados financeiros, maiores os custos potenciais da abertura frente aos benefícios potenciais. Na seqüência desse trabalho, um estudo mais amplo (Edison et. al., 2002) também não encontrou vínculos sólidos entre a liberalização financeira e o crescimento dos países em desenvolvimento.

Prasad et. al. (2003) aprofundam a análise realizada em IMF (2001) e Edison et. al (2002), a partir do estudo sistemático de 76 países industrializados e em desenvolvimento para o período 19601999, e de uma extensa revisão da literatura ${ }^{7}$. Concluem haver uma distância não desprezível entre as promessas dos modelos teóricos convencionais e a realidade alcançada pelos países em

acerca da necessidade do estabelecimento de uma seqüência apropriada para aberta foi relegado a um plano secundário (Edwards, 1995, 2002). Depois da crise mexicana e, fundamentalmente, da crise asiática, temas como a seqüência da abertura da conta capital e regulação prudencial dos sistemas financeiros domésticos voltaram à ordem do dia. A posição dos relatórios oficiais do FMI e Banco Mundial foi refletindo esta nova perspectiva. Na academia, algumas vozes se levantaram com mais vigor. Rodrik (1998) sugeriu, por exemplo, que a abertura financeira não estaria associada a um maior crescimento, ao longo dos anos 1990. Posteriormente, o mesmo autor criticou os desequilíbrios entre os custos institucionais da promoção de reformas liberalizantes e os resultados efetivos em termos de desenvolvimento (Rodrik, 2001). Radalet \& Sachs (1998), Furman \& Stiglitz (1999) e Stiglitz (2002) questionaram a assimetria de resultados no processo de globalização e a "imparcialidade" do FMI na condução da gestão "política" das crises financeiras dos anos 1990 .

${ }^{5}$ Trata-se do capítulo quatro do World Economic Outlook de outubro de 2001, denominado de "Integração Financeira Internacional e os Países em Desenvolvimento".

6 "Esses benefícios potenciais de longo prazo [ampliação dos investimentos, spill overs derivados do investimento direto externo e o aprofundamento dos mercados financeiros], precisam, todavia, ser confrontados com os perigos que os mercados financeiros internacionais abertos também podem criar, incluindo crises financeiras, com elevado custo em termos de produto. Os problemas estão geralmente associados com a entrada e saída excessiva de capitais e, de um modo mais geral, com a volatilidade dos fluxos líquidos de capital ... [essa volatilidade] tem crescido substancialmente ao longo do tempo, especialmente em países que experimentaram liberalizações da conta capital mais extensivas. $\mathrm{O}$ aumento da volatilidade tem sido mais pronunciado nos fluxos de portfólio do que nos fluxos de IDE, refletindo as relações de mais longo prazo implícitas ao IDE. A volatilidade tem sido particularmente alta nos anos 1990, quando da liberalização recente de muitos países em desenvolvimento. Nessa década, a "maior volatilidade dos fluxos de capital tem, também, estado associada a um menor crescimento." (IMF 2001:161)

${ }^{7}$ Os autores destacam que dos 14 estudos mais recentes que procuraram avaliar as ligações entre liberalização financeira e crescimento, e que utilizaram os mais variados métodos estatísticos, somente 3 sinalizaram alguma relação positiva. Em seu próprio estudo, Prasad et.al (2003) procuram associar indicadores de abertura financeira (estoques de ativos e passivos financeiros com respeito à renda) com indicadores de crescimento, utilizando diversas variáveis de controle, usuais em estudos de crescimento econômico (escolaridade, qualidade das instituições, nível inicial de renda, etc.). Em todas regressões os resultados foram considerados decepcionantes. 
desenvolvimento. A teoria apontaria diversos canais (diretos e indiretos) pelos quais a integração financeira ${ }^{8}$ poderia estimular o crescimento. Os fluxos de capitais teriam vários benefícios diretos. Ampliariam a poupança mobilizável pelos países em desenvolvimento e a taxa de retorno (ajustada ao risco) para os provedores do capital, os países industrializados. Permitiriam, ainda, a transferência de tecnologia, a pulverização do risco com resultados mais eficientes em termos de alocação de recursos e, por fim, o desenvolvimento dos mercados financeiros nos países receptores. Os efeitos indiretos estariam associados à promoção da especialização produtiva, via investimento direto externo, e a indução à adoção de políticas econômicas e instituições mais "saudáveis", na medida em que tais elementos passaram a ter um peso crescente na decisão de alocação de recursos dos investidores.

Em conjunto, tais efeitos diretos e indiretos, dariam base para a expectativa de que uma maior integração financeira seria capaz de promover um maior crescimento. Todavia, as evidências empíricas levantadas e a revisão literatura sugerem uma conclusão distinta. Não seria possível provar a existência de um vínculo estreito entre abertura financeira e crescimento e, o que é pior, tal abertura tenderia a gerar maior instabilidade doméstica". Vale dizer, “.... enquanto não há provas nos dados de que a globalização financeira tenha beneficiado o crescimento, há evidências de que alguns países possam ter experimentado como resultado uma maior volatilidade do consumo." (Prasad et. al., 2003: 6).

Da mesma forma que no estudo anterior do Fundo, sugere-se que os países com instituições e políticas transparentes e alinhadas às melhores práticas internacionais teriam condições de explorar os benefícios potenciais da integração financeira. $\mathrm{Na}$ verdade, esta é a principal derivação de política gerada por Prasad et. al (2003). Diante da fragilidade das evidências, o otimismo com voluntarismo de mercado (potencializado por pressões políticas vindas de Washington) do início dos anos 1990, foi agora reduzido à constatação de que a "integração financeira deve se abordada de forma cautelosa, com boas instituições arcabouços macroeconômicos vistos como importantes ...” (p.5). E mais, que o tratamento destes aspectos institucionais deveria ser adequado às especificidades de cada país.

Conforme será detalhado no próximo item, deve-se notar que este tipo de avaliação reforça a agenda de reformas da arquitetura financeira internacional, que enfatiza o papel dos países receptores do capital enquanto elos centrais na cadeia de estabilização dos mercados financeiros internacionais. Por isso mesmo, o esforço do Fundo, do Banco Mundial, dos governos do G7 e demais órgãos multilaterais em parametrizar e disseminar melhores práticas e modelos de instituições favoráveis aos mercados,. Há, portanto, uma ênfase nas reformas estruturais na periferia capitalista em detrimento da criação/fortalecimento de arranjos institucionais multilaterais. Legitima-se, em simultâneo, essa função ampliada do Fundo e do Banco Mundial. Isto não é desprezível se for lembrada a forte pressão política de setores conservadores (especialmente dos EUA) que, em meio às crises dos anos 1990 e aos megapacotes de socorro, clamavam pela redução do papel daquelas instituições (Meltzer, 2000). Fortaleceram-se argumentos que apontavam o problema do risco moral que seria induzido pelos socorros, e a defesa dos contribuintes que estariam financiando a ineficiência de governos corruptos localizados em países exóticos (Goldstein, 2001).

Por outro, uma leitura mais cautelosa sobre os efeitos da liberalização financeira também abre espaço para a consideração de que podem ser válidos controles temporários sobre os capitais

\footnotetext{
${ }^{8}$ É importante destacar a diferença entre o que o estudo considera globalização financeira, ou seja, a constituição de um mercado financeiro global a partir da redução das restrições à livre mobilidade de capitais, e o que seria a integração financeira, definida a partir das ligações entre um país individual e aquele mercado.

9 “(...) o exame sistemático das evidências sugere que é difícil estabelecer uma relação causal robusta entre o grau de integração financeira e o desempenho em termos de crescimento econômico. Na perspectiva da estabilidade macroeconômica, o consumo é tido como uma melhor medida do que o produto; então, flutuações no consumo são percebidas como tendo um impacto negativo no bem-estar econômico. Há pouca evidência de que a integração financeira tenha auxiliado os países em desenvolvimento a melhor estabilizar as flutuações no crescimento do consumo, em que pesem os amplos benefícios que, teoricamente, os países em desenvolvimento poderiam obter neste aspecto." (Prasad et. al, 2003: 6).
} 
(especialmente na entrada), com o intuito de alterar o perfil temporal dos investimentos, de modo a reduzir sua volatilidade potencial, ou, ainda, garantir fôlego para a execução de um processo mais amplo de "modernização institucional". Não à toa, o Fundo vem realizando avaliações sistemáticas sobre as diversas experiências de controle de capitais. Em Ariyosh et. al (2000), por exemplo, reforçase a percepção de controles temporários sobre os movimentos de capitais podem ser necessários e ter efeitos positivos. A recente discussão tornada pública pela Vice-Diretora Gerente do Fundo, Anne Krueger (2001), de adaptação, para a esfera internacional e para o caso de governos soberanos, da legislação de falências dos EUA, previa, inicialmente, mecanismos de "moratória" como parte de um processo mais amplo de renegociação de dívidas insustentáveis ${ }^{10}$. Nesta mesma linha, o Diretor do Departamento de Pesquisa do FMI (Rogoff, 2002) sugere que, diante das evidências de que o mix de benefícios e riscos associados à liberalização financeira não autoriza o otimismo de uma década atrás, deve-se olhar mais pragmático para temas como o controle de capitais.

Assim, dever-se-ia separar o joio do trigo, no sentido de discriminar os tipos instrumentos financeiros que geram maiores riscos e menores benefícios. Um primeiro recorte seria entre aporte de capital (equity) e o endividamento (debt), onde não se deveria obstaculizar o investimento direto externo (por ser a mais estável fonte de financiamento externo e por aportar tecnologia e capacidade gerencial) e, mesmo, modalidades de investimento em portfólio capazes de gerar uma necessária diversificação de riscos. Por outro lado, os instrumentos de dívida (de curto prazo) poderiam ser desencorajados em muitas circunstâncias, ainda que com cuidado de não se comprometer o afluxo de recursos que não tem associação direta com posições especulativas, como os créditos comerciais. Além disso, o foco de qualquer política deveria ser na utilização de restrições temporárias à livre mobilidade de capitais, sempre que com o objetivo de se evitar o excesso de entrada ou saída de recursos. Rogoff (2003) considera que o balanço geral das experiências com a utilização de controles segue sendo negativo. Todavia, na medida em que o próprio balanço sobre os efeitos concretos da liberalização financeira também se mostra desfavorável, cria-se espaço para uma abordagem cautelosa e específica a cada caso quando se trata de reduzir o grau de conversibilidade da conta capital.

\section{Crises Financeiras e Estabilizadores Automáticos}

É importante resgatar algumas tentativas de racionalização de Prasad et. al. (2003) para os resultados "decepcionantes" (na medida em que negam o otimismo liberalizante predominante no establishment oficial e privado) das evidências empíricas constatadas em seu estudo. A volatilidade no consumo (proxy da instabilidade macroeconômica, em termos de bem-estar de uma sociedade), maior nas economias em desenvolvimento "mais integradas", seria o resultado do fato de que a liberalização financeira, ao ampliar a restrição orçamentária dos agentes domésticos, gera um boom de consumo que se transforma em bust quando da ocorrência das crises financeiras. Essas seriam mais freqüentes e intensas quanto mais frágeis as instituições domésticas, especialmente no que se refere à regulamentação dos sistemas financeiros, a transparência das informações e arranjos legais, etc. A tradição do mainstream da economia coloca a instabilidade financeira, manifesta em crises com distintos padrões (de balanço de pagamentos em conta corrente, cambiais, bancárias, "gêmeas", em conta capital, etc.), como algo que emerge de anomalias ante o comportamento (teoricamente) eficiente dos mercados (Malkiel, 2003, Shiller, 2003).

\footnotetext{
${ }^{10}$ Conforme analisado por Cunha (2002) as pressões dos investidores privados foram alterando o modelo inicialmente exposto por Anne Krueger. Em especial, o tema de suspensão, mesmo que temporária, do pagamento de dívidas, mostrou-se com sendo um dos mais polêmicos.
} 
Por isso mesmo, as várias famílias de modelos de crises cambiais, bancárias, "gêmeas", etc., enfatizam que a origem das rupturas está normalmente associada a desequilíbrios macroeconômicos e institucionais (Mishkin, 1992, IMF, 1998, Andrade \& Silva, 1999, Prates, 2003). Nas últimas três décadas, há uma nítida predominância de crises localizadas nas economias em desenvolvimento. Muitos apontam essa característica como um dos fatos estilizados marcantes da globalização financeira do final do século XX (Bordo et al., 1999, Bordo \& Flandreau, 2001, World Bank, 2001, Cepal, 2002, Unctad, 2001). Não à toa, a busca da estabilidade perdida, nos anos 1990, teve como pressuposto básico a percepção que os "emergentes" eram a fonte principal da instabilidade global (Greenspan, 1997). Este ponto será resgatado no item 4 deste trabalho. Aqui, o que se pretende enfatizar é que a tradição teórica baseada nos trabalhos de Keynes e Minsky, gera um conjunto de insights mais adequados ao enfrentamento das características recentes da instabilidade financeira, e que estão na origem das constatações dos recentes trabalhos do FMI (IMF, 2001, Edison, 2002, Prasad et. al., 2003). Ou seja, se é verdade que não há um vínculo automático entre liberalização financeira e crescimento, e, pelo contrário, se a liberalização parece ampliar a volatilidade macroeconômica e potencializar o risco de crises (Demirgüç-Kunt \& Detrigiache, 1998), então a reflexão em torno da criação de um ambiente internacional mais saudável, porque capaz de compatibilizar crescimento e abertura, deve estar alicerçada em um referencial analítico que tenha na instabilidade um elemento central (e não uma anomalia circunstancial). Com isso, poder-se-ia derivar uma agenda ampliada de medidas que visem a “estabilização de economias instáveis" (Minsky, 1986)

A tradição fundada em Keynes e Minsky rejeita as noções de eficiência dos mercados e de que os bancos nas economias capitalista são meros intermediários de recursos entre poupadores e investidores. As "falhas dos mercados financeiros" - informações imperfeitas e assimétricas, impossibilidade dos mercados coordenarem decisões interdependentes, comportamento míope dos bancos num contexto de expectativas otimistas, etc. - seriam constituintes das economias capitalistas modernas, nas quais predomina a moeda de crédito, emitida pelos bancos (Chick, 1988). Nesse sentido, a teoria da instabilidade financeira de Minsky parte da elaboração de Keynes sobre as economias monetárias de produção ${ }^{11}$ e introduz a noção de que a instabilidade das economias capitalistas está associada à evolução das condições de financiamento dos agentes e ao comportamento dos preços dos ativos financeiros em relação ao preço da produção corrente ao longo do ciclo econômico. Em um mundo incerto, as decisões de investimento baseiam-se na avaliação prospectiva do preço dos ativos, constituído por três elementos: as rendas esperadas $(q)$, seus custos de carregamento $(c)$ e o prêmio de liquidez $(l)$. As relações de débito e crédito, entre investidores e seus financiadores, faz com que os custos de carregamento dos primeiros estejam diretamente vinculados às rendas esperadas dos segundos.

Os passivos dos agentes são vistos como um fluxo de pagamentos no tempo, ao passo que os ativos também geram uma expectativa de rendas ao longo do tempo. A perspectiva temporal do balanço patrimonial dos agentes determina um certo tipo de estrutura financeira, onde: (i) diz-se que há uma posição hedge quando os fluxos de caixa - determinados pelo desempenho operacional e/ou receitas derivadas do cumprimento de obrigações contratuais de terceiros - superam de forma segura, em um horizonte de tempo razoável, os seus pagamentos correntes, contratuais e contingenciais; (ii) está-se especulativo quando as receitas esperadas são suficientes somente para o pagamento de parte dos compromissos passivos - os juros, mas não o principal - o que determina a necessidade de rolagem

\footnotetext{
11 "Eu tomo o insight fundamental de Keynes de que existem dois níveis de preço em uma economia capitalista, e que seus determinantes são bem distintos. Um é a produção corrente e os salários que, quando combinados com as condições de financiamento, geram as condições de oferta dos investimentos. O outro é o capital e os ativos financeiros que, quando combinados com as condições de financiamento, geram a demanda por investimentos. Os preços de oferta dos investimentos podem ser vistos como o mark up sobre os custos laborais, enquanto que o preço do capital e dos ativos financeiros é a capitalização dos fluxos de caixas esperados no futuro, dos lucros futuros em um mundo incerto." (Minsky, 1991:159)
} 
das dívidas; e (iii) está-se Ponzi quando há que se emitir novas dívidas para honrar seus pagamentos, dado que suas rendas correntes e contratuais são insuficientes até para o pagamento dos juros.

As situações de fragilidade financeira seriam inerentes aos ciclos econômicos. As crises financeiras constituir-se-iam em um componente essencial da fase descendente desses ciclos, os quais seriam sustentados pela expansão do crédito pelos bancos. Estes são agentes capitalistas que visam lucro e tendem a expandir os empréstimos, nem sempre ancorados em uma avaliação adequada dos riscos - especialmente num contexto de expectativas otimistas e/ou de crescimento econômico -, sancionando a demanda de crédito das empresas e das famílias. No auge do ciclo, a tentativa das A.M.s conterem a expansão creditícia é, em geral, ineficaz, pois os bancos buscam burlar, permanentemente, as restrições impostas mediante a introdução de inovações financeiras.

A elevação do preço dos ativos financeiros em relação aos ativos instrumentais estimularia ainda mais a demanda de crédito, que se mantém elevada enquanto as expectativas são favoráveis. Apenas quando ocorre a reversão cíclica - devido a mudanças adversas nas condições macroeconômicas e/ou à reversão daquelas expectativas - a fragilidade financeira se explicita. Quando isto ocorre, as famílias e empresas procuram liquidar seus ativos na tentativa de saldar suas dívidas e os bancos restringem o crédito, diante do aumento dos riscos de inadimplência e da redução do valor dos colaterais. Com o estabelecimento de dificuldades generalizadas para o refinanciamento de suas posições devedoras, os agentes tendem a reduzir seus gastos - especialmente os capitalistas, que contraem os investimentos, determinando uma queda no nível de emprego. A crise financeira torna-seia uma crise econômica real ${ }^{12}$. Ainda assim, as recessões poderiam não se converter em processos deflacionários cumulativos. A intervenção das A.M.s, provendo liquidez ao sistema, e o estímulo autônomo da demanda agregada através da expansão do gasto público, poderiam amenizar as crises, criando, simultaneamente, as condições para a recuperação. Estes seriam os "estabilizadores automáticos" necessários para reduzir o potencial disruptivo da instabilidade financeira.

O plano de Keynes para o ordenamento da economia internacional no pós-guerra trazia esse tipo de preocupação. O seu "banco central internacional" (Clearing Union) poderia regular a liquidez de uma divisa internacional (bancor), de modo a estabilizar os padrões de pagamento, minimizando-se o risco de desvalorizações/valorizações excessivas das moedas domésticas. Tal "estabilizador automático" ampliaria os graus de liberdade dos governos nacionais em realizar as políticas anticíclicas necessárias para a manutenção do pleno emprego e, assim, da estabilidade social e política, nos marcos de democracias liberais e economias de mercado. Como se sabe, Keynes recuou de sua "agenda ampla" e teve de defender a "agenda mínima" imposta pelo Tesouro dos EUA (Keynes, 1943, 1944, Davidson, 1992 e Ferrari Filho, 1999). A política impô-se à razão econômica, na medida em que o modelo de arranjos institucionais propostos por Keynes teria reduzindo o grau de dependência dos vários governos com respeito às decisões do país N-1, emissor da divisa chave no modelo vencedor dos norte-americanos. O “dilema de Triffin”, que tornou-se uma inescapável realidade nos final da década de 1960, provou que o Sistema de Bretton Woods não foi capaz de trazer um equilíbrio maior nas relações entre países "superavitários" e "deficitários". E, mais, que diante das tensões entre realizar objetivos de política doméstica e o papel de fiel depositário do equilíbrio no padrão de pagamentos internacionais, os EUA não hesitaram em optar pelos interesses domésticos (Eichengreen, 1996).

\footnotetext{
12 "Uma crise financeira ocorre quando há uma necessidade generalizada de realizar posições pela venda [de ativos], o que resulta em uma forte e generalizada queda no preço dos ativos. Como resultado, compromete-se a solvência, valorada a preços de mercado, de um grande número de instituições. Isto leva à ampliação dos problemas de refinanciamento. (...) A crise financeira leva a uma crise econômica quando o investimento cai e, assim, declinam os lucros, produção, emprego e salários. A queda nos lucros conduz a uma nova queda no preço dos ativos (o numerador da relação de capitalização cai) e a um novo declínio na capacidade das unidades realizarem seus compromissos financeiros. Em tal ambiente, há uma grande retração no funding para investimentos [no crédito]. Seguem novas quedas no emprego, produção, salários e lucros.” (Minsky, 1991:163)
} 
Assim, ao se assumir a perspectiva de Keynes e Minsky, chega-se a seguinte constatação: “(a) hipótese da instabilidade financeira é pessimista. O capitalismo é imperfeito e ameaçado por crises econômicas e financeiras, que são endógenas. Uma estrutura institucional e um padrão de intervenções podem atenuar o risco de mau funcionamento, mas cada sucesso na contenção [das crises] leva a novas elaborações das relações financeiras e econômicas, que tornam o sistema mais propenso às crises. O sucesso é um fenômeno transitório, embora a era iniciada em 1946 tenha demonstrado que o tempo de transição pode ser bem longo." (Minsky, 1991:165). O desafio, portanto, é o de se estar atento às transformações na dinâmica dos mercados para a criação de instituições mais ajustadas ao papel de "estabilizadores automáticos". Vários autores ${ }^{13}$ contemporâneos estão buscando superar as hipóteses restritivas do modelo original de Minky, centradas na análise dos ciclos financeiros em economias maduras e sujeitas a baixa mobilidade de capitais. Assim, busca-se incorporar as transformações financeiras em curso desde a adoção do sistema de taxas de câmbio flutuantes após o colapso de Bretton Woods, e a especificidades das economias periféricas, como a dependência de fontes de financiamento externas e a ausência de moedas conversíveis.

Em um contexto de expansão da liquidez financeira internacional, desregulamentação e integração dos mercados, criou-se uma supremacia da "economia de ativos", onde os ciclos econômicos ficam determinados pela evolução dos preços dos ativos financeiros e não mais pela dinâmica dos investimentos produtivos e pela evolução dos preços dos ativos instrumentais. Flexibiliza-se, assim, a hipótese de Minsky de subordinação dos mercados de ativos financeiros aos mercados de ativos produtivos e de crédito. No ciclo econômico dominado pela dinâmica financeira, a emergência de situações de fragilidade financeira estaria associada a booms especulativos nos mercados de ativos financeiros, alimentados pela expansão do crédito bancário num ritmo superior ao da produção. Tal fragilidade permaneceria encoberta na fase ascendente do ciclo, enquanto a valorização do preço dos ativos se mantivesse. A inflação de ativos, por sua vez, estimularia ainda mais o endividamento dos agentes, devido ao efeito-riqueza. Essa trajetória de elevação do preço dos ativos e do crédito tenderia a ser insustentável no longo prazo. Mas o momento de reversão do ciclo financeiro seria desconhecido a priori. A reversão seria provocada por um acontecimento súbito e inesperado - como um aumento da taxa de juros - que resultaria na deflação do preço dos ativos, seguida pela contração do crédito.

A recessão induzida pelas finanças também possuiria características peculiares. As famílias não desempenhariam o papel estabilizador observado nas recessões precedentes. Pelo contrário, reforçariam a fase descendente do ciclo. Diante da restrição financeira provocada pela queda do preço dos ativos e pelo aumento do serviço das dívidas num contexto de taxas de juros reais elevadas, as famílias procurariam aumentar sua poupança financeira - e, assim, reduziriam o consumo - como forma de compensar a queda da riqueza financeira. Além disso, o corte dos investimentos produtivos do setor privado - com o objetivo de elevar a taxa de autofinanciamento - não tenderia mais a ser contrabalançado pelo aumento do gasto público, como supunha Minsky. Assim, todas estas características do ambiente de finanças globalizadas e desregulamentadas induziriam a necessidade de uma agenda de mudanças institucionais capazes de minimizar o potencial de instabilidade revelado, entre outros, por estudos como os de IMF (2001), Edison (2002) e Prasad et. al. (2003).

$\mathrm{Na}$ ótica predominante nos meios acadêmicos, oficiais e privados, a assim-chamada "reforma na arquitetura financeira" internacional traduziria a busca da estabilidade perdida, através do fortalecimento das instituições domésticas dos países em desenvolvimento e a readequação do papel das agências multilaterais. Nesse sentido, Krueger (2003c) avalia o no papel do FMI nos marcos mais gerais das transformações do sistema financeiro internacional nas últimas décadas. A Vice-Diretora

13 Ver, dentre outros, Aglietta (1995), Griffith-Jones (1995), Belluzzo \& Coutinho (1996), Chesnais (1996), Kregel (1998), Paula \& Alves Jr. (2000), Unctad (2001), Cepal (2002), Prates (2003) e Amado (2003). 
Gerente do Fundo destaca que, apesar as transformações do sistema financeiro mundial e da adaptação dos meios de ação, a missão do FMI $^{14}$ seguiria a mesma: a prevenção de crises financeiras e, quando isso não for possível, a resolução das crises. No cumprimento dessas tarefas, o "núcleo" do trabalho do Fundo estaria na função de supervisão da implementação de políticas econômicas (monetária, fiscal e cambial) e de parâmetros institucionais ajustados às melhores práticas internacionais. Todavia, a mudança na natureza das crises imporia a necessidade de uma adequação de métodos.

Assim, antes da década de 1970, o Fundo tinha de enfrentar crises de balanço de pagamentos (em conta corrente), onde se constatava uma inadequação das condições domésticas com a sustentação do compromisso de se sustentar taxas de câmbio fixas. Políticas macroeconômicas que implicassem em um nível de inflação muito superior à média internacional, ou choques nos termos de troca, sinalizariam para a possibilidade de rupturas. Normalmente, nos meses que antecediam tais crises, os principais leading indicators eram as políticas domésticas expansionistas e o crescimento (antecipatório de uma desvalorização) das importações com contração das exportações. A perda crescente de reservas internacionais anunciava a ruptura eminente. Os pacotes de socorro financeiro do Fundo eram suficientes para normalizar as transações comerciais e de serviços, e vinham acompanhados de ajustes macroeconômicos que visam ajustar a absorção doméstica à capacidade de pagamentos externa.

O regime de câmbio flexível tornou-se dominante a partir de 1973, com o fím do compromisso de manutenção de taxas fixas entre as principais divisas internacionais. Todavia, não foi capaz de cumprir a promessa de que as flutuações na taxa de câmbio funcionariam como estabilizadores automáticos, garantindo, em simultâneo, o ajuste dos balanços de pagamentos e a liberdade para a adoção de políticas monetárias melhor ajustadas à busca do equilíbrio doméstico. Do ponto de vista dos países em desenvolvimento, muitos dos quais mantendo suas moedas atreladas às divisas-chaves, o problema central passou a ser a sustentabilidade dos passivos externos. Na década de 1990, a globalização financeira e a maior integração aos circuitos mais dinâmicos dos mercados de capitais, tornou a questão da conversibilidade da conta capital o calcanhar de Aquiles dos países periféricos. O novo ciclo de endividamento modificou o perfil das dívidas, agora predominantemente junto a fontes privadas, e com um elevado grau de pulverização.

Para Krueger (2003c) os eventos dos anos 1990 levaram o Fundo à necessidade de compreender melhor a natureza das crises da "conta capital"15. Quais seriam as suas especificidades? Em síntese $\mathrm{e}^{16}$, poder-se-ia dizer que: (i) elas podem ocorrer de forma mais rápida, na medida em que não dependem mais somente do volume de transações correntes mas, também, do estoque (e liquidez) dos instrumentos de dívida; (ii) estão sujeitas a um maior grau de subjetividade, pois ocorrem sempre que há uma perda de confiança dos investidores, o que nem sempre está associado à existência de problemas econômicos fundamentais; e (iii) com o predomínio das finanças diretas, os detentores de títulos de dívida que, "legitimamente" têm motivos para desconfiar da sustentabilidade das políticas e instituições podem, rapidamente, acionar sinais de "venda" dos seus ativos. Além disso, a adoção

\footnotetext{
${ }^{14}$ O FMI é, e tem sido sempre, uma organização associativa. Sua missão é 'promover a cooperação monetária internacional ...; facilitar a expansão e equilíbrio no crescimento do comércio internacional ...; prover assistência no estabelecimento de um sistema multilateral de pagamentos ...; tornar os recursos do Fundo temporariamente disponíveis [aos seus membros] sob salvaguardas adequadas, provendo, então, a oportunidade para eles corrigirem desajustes nos seus balanços de pagamentos; e reduzir a duração e intensidade do desequilíbrio no balanço de pagamentos internacional dos seus membros'." (Krueger, 2003).

15 Essa "confissão" reforça as críticas externas, pela "direita" e a "esquerda", de que o FMI não estaria diagnosticando e tratando adequadamente as crises dos anos 1990. Ver Meltzer (2000) e Stiglitz (2002), para citar dois exemplos notórios.

${ }^{16}$ Essa perspectiva que já encontrava eco na literatura não ortodoxa, como em Griffith-Jones (1995), Belluzzo \& Coutinho (1996), Akyüz \& Cornford (1999), Yoshitomi \& Shirai (1999), entre outros, foi sendo incorporada nos modelos convencionais com Calvo \& Mendoza (1997), Calvo (1998), Schneider \& Tornell (1999, 2000). Uma revisão dessa literatura pode ser encontrada em Andrade \& Silva (1999) e Prates (2003).
} 
generalizada entre os países emergentes de regimes cambiais mais rígidos, abriu espaço para a emergência de crises de confiança quanto à manutenção da conversibilidade.

Com esse tipo de crise, segue Krueger (2003c), o "tratamento" mais adequado seria a busca do resgate da confiança dos investidores na capacidade de cada país honrar os serviços de suas dívidas. Isto implicaria uma maior atenção à questão da gestão da dívida por parte de governos soberanos, mesmo aqueles capazes de adotar políticas macroeconômicas consideradas "saudáveis". Nesse sentido, o FMI estaria mais cético quanto aos benefícios de regimes de câmbio fixo (que induziriam ao agora perigoso sobre-endividamento em divisas) e mais ativo na indução de reformas estruturais associadas à regulação dos mercados financeiros e adoção de arranjos institucionais mais transparentes (para a execução de políticas fiscal e monetária, na governança corporativa, em legislações de falência, etc.). Tais elementos seriam centrais para a prevenção das crises. Já no caso de gerenciamento de crises, Krueger (2003c) destaca que Fundo ainda tem um papel importante a desempenhar, não só no que se refere à implementação de medidas corretivas e no aporte de recursos financeiros mas, sobretudo na busca de coordenar os demais atores envolvidos nos processos de reestruturação de dívida. Aqui, coube um destaque especial ao estímulo à adoção de cláusulas de ação coletiva nos (novos) contratos de dívida soberana. Curiosamente, a Vice-Diretora Gerente do FMI não mencionou o esforço recente, liderado por ela, em convencer o establishment da necessidade de se criar mecanismos estatutários para a resolução de conflitos entre credores e devedores, nos moldes do modelo norte-americano de falência ${ }^{17}$. Como em outros momentos da história, reformas mais amplas na macroestrutura política que dá para o desenvolvimento dos mercados privados, foram obstaculizadas, em que pese seu apelo racional. Esse ponto será explorado a seguir.

\section{A Agenda Perdida das Reformas na Arquitetura Financeira Internacional}

A recorrência de crises financeiras e a retração na entrada líquida de capitais nos países em desenvolvimento precipitou um intenso debate teórico e político ${ }^{18}$. Buscavam-se as razões da instabilidade e os mecanismos necessários a sua minimização. Havia um ponto central que tendia a diferenciar dois grupos de explicações e recomendações de políticas: a questão da origem das crises, se nos países receptores de capital, ou se no funcionamento geral dos mercados globalizados. A partir desse recorte é possível localizar, de um lado, os modelos e análises empíricas que enfatizavam as fragilidades macroeconômicas e institucionais dos países em desenvolvimento. E, de outro, análises que, sem negar os problemas específicos dos "emergentes", destacavam os comportamentos irracionais dos investidores dos países credores e as falhas estruturais dos mercados financeiros globalizados e desregulamentados. De cada conjunto de explicações podia-se derivar propostas de ajuste. No primeiro caso, consolidou-se o que se poderia chamar de uma "agenda mínima de reformas", identificada pela criação e disseminação de melhores práticas em diversas áreas de política econômica e padrões institucionais. Do segundo conjunto de explicações emergiria uma "agenda ampliada de reformas", que enfatizaria a necessidade de se criar/fortalecer órgãos e regras de caráter multilateral capazes de equilibrar as relações (assimétricas) entre credores e devedores.

Assim, deve-se ressaltar que há uma relação estreita entre o debate acadêmico a conformação das políticas de ajuste macroeconômico propostas pelos órgãos multilaterais, com o apoio dos governos do G7. A visão convencional de que as crises cambiais do final dos anos 1970 e início dos anos 1980, eram o resultado da inconsistência fiscal corrente de políticas domésticas expansionistas, gerou uma agenda política pautada pela ênfase na adoção do bom comportamento fiscal e monetário (Krugman,

\footnotetext{
${ }^{17}$ Cunha (2002) analisa as propostas de equacionamento das crises de endividamento.

${ }^{18}$ Um resenha dessa literatura pode ser encontrada em IMF (1998), Aziz et. al (2000), Eichengreen (1999), Andrade \& Silva (1999), Goldstein (2001), Furman \& Stiglitz (1999), Radalet \& Sachs (1998), entre outros.
} 
1997). As crises dos anos 1990, suscitaram a criação de novos modelos teóricos, que passaram a enfatizar os efeitos intertemporais de políticas "potencialmente inconsistentes" e das falhas institucionais - como a existência de garantias implícitas sobre os empréstimos bancários ou o too big to failure. A agenda de ajuste, como destacou Krueger (2003c), passou a enfatizar as reformas estruturais nos mercados emergentes, entendidas agora em um sentido mais amplo, o que incluiria a adoção de melhores práticas em várias áreas.

Os fóruns multilaterais oficiais e $\operatorname{privados}^{19}$ têm trabalhado no sentido da identificação e disseminação de parâmetros regulatórios globais, a partir da experiência dos países centrais. Enfatizase, também, a necessidade dos governos nacionais, nos países em desenvolvimento (devedores), adotarem tais padrões. Entende-se que isso minimizaria a tendência de risco crescente associada às decisões de investimento em ativos pouco transparentes. Ou seja, os mercados emergentes se caracterizariam por apresentarem graves falhas institucionais, tanto na supervisão dos seus sistemas financeiros, quanto na qualidade da governança estatal e empresarial. Com informações econômicofinanceiras pouco transparentes, corrupção e insuficiências governamentais no que concerne à regulamentação dos mercados financeiros, gerenciamento do endividamento público, implementação das políticas macroeconômicas, etc., o risco dos investidores internacionais ficaria super-dimensionado, ampliando, conseqüentemente, o potencial global de instabilidade.

Em uma visão retrospectiva, pode-se argumentar que ao identificar nos países emergentes a fonte da instabilidade, o establishment oficial e privado ${ }^{20}$ emitiu um sinal no sentido da manutenção dos mecanismos contratuais privados, nos marcos predominantes no processo recente de integração financeira internacional (Fischer, 1999 e 2000, Summers, 1999, Meltzer, 2000, IMF 2000, G7, 2000, Council of Foreing Relations, 1999, Truman, 2001). As reformas deveriam ser pontuais. A constituição de instituições reguladoras globais - um tribunal internacional para a arbitragem de conflitos de dívidas, um banco central internacional, uma agência reguladora das finanças, uma companhia internacional de seguro de crédito, etc. - com poder de coerção sobre os países centrais (credores), não estava na "agenda mínima". Elementos dessa perspectiva pouco convencional poderiam ser encontrados em sugestões de especialistas da academia e do mercado (Sachs, 1995, Garten, 1998, Eatwell \& Taylor, 1998, Soros, 1998, Rogoff, 1999, Unctad, 2001, Rodrik, 2002, Stiglitz, 2002).

Três pontos sustentavam a racionalidade das propostas da "agenda ampliada". Em primeiro lugar, argumentava-se que as instituições herdadas de Bretton Woods teriam nascido em um mundo onde a liberdade irrestrita aos fluxos de capitais era entendida como sendo incompatível com o objetivo maior: a manutenção da estabilidade cambial com expansão do comércio sob bases multilaterais. Por conta disso, nem o FMI, nem o Banco Mundial ou o GATT/OMC, possuiriam mecanismos legais capazes de dar conta da regulação da conta capital, nos marcos do estágio recente de avanço na integração financeira internacional. Sustentava-se, também, que a internacionalização dos negócios teria modificado radicalmente as bases geográficas da regulação. Sem uma contrapartida adequada, em termos de regras e poder de coerção, também globais, haveria uma tendência permanente de instabilidade. Isto porque, segue o terceiro argumento, os investidores privados tenderiam a explorar os diferenciais regulatórios, potencializando os comportamentos miméticos e irracionais dos booms and

\footnotetext{
${ }^{19}$ G7, FMI, Banco Mundial, BIS, OCDE, Financial Stability Forum, entre outros, bem como comitês que agregam representantes dessas instituições. No setor privado, destaca-se a atuação do Institute of International Finance, que através de vários comitês expressa a visão e os interesses de cerca de 320 instituições financeiras que operam em 60 países (www.iif.com).

${ }^{20}$ Evidentemente não havia homogeneidade nas visões das diversas instâncias multilaterais. No âmbito das discussões do G7, o governo inglês propôs a criação de uma superagência global de regulação financeira, a partir da fusão do FMI, BM e BIS; a França, com o intuito de reduzir a influência dos EUA nas decisões do FMI, sugeriu ampliar o poder decisório do Comitê de Ministros das Finanças do Fundo; a Alemanha defendeu as target zones para as principais divisas internacionais, como forma de reduzir a instabilidade; e o Canadá alinhouse à defesa de um maior poder de arbítrio do FMI sobre os credores, inclusive com a invocação de suspensão temporária do pagamento de dívidas em caso de crise (Einchengreen, 1999)
} 
busts dos ciclos financeiros recentes ${ }^{21}$. Além disso, considerava-se como central a percepção de que existe uma assimetria, entre credores e devedores, com um viés para os primeiros, no que se refere à distribuição dos custos e benefícios do processo de globalização financeira. Diante das propostas de reformas da "agenda mínima", entendia-se que a ênfase na adoção de parâmetros regulatórios globais imporia um custo desproporcional sobre os governos nacionais dos países em desenvolvimento (Unctad, 2001, Rodrik, 2001, 2002).

Parte do espírito pouco convencional das propostas da "agenda ampliada" foi incorporada pelo FMI na discussão sobre a necessidade de se criar mecanismos estatutários para o equacionamento conflitos entre credores (privados) e devedores (soberanos). Ou, mais precisamente, da criação de um "mecanismo para a reestruturação de dívidas soberanas" (SDRM, em inglês). Tal proposição foi de encontro à visão dominante no setor privado, que propõe a manutenção da idéia de livre negociação ou, no limite, que admite a introdução de inovações contratuais dos instrumentos de dívida, de modo a se estabelecer, ex-ante, procedimentos majoritários para o caso de um default. Nos últimos três anos este tem sido um ponto relevante dos debates oficiais e de segmentos do setor privado (Miller, 2002, Rogoff \& Zettlemeyer, 2002, Krueger, 2001 e 2002, Roubini, 2002, Taylor, 2002), na medida em que introduziria um elemento extremamente heterodoxo no ordenamento das finanças internacionais.

A proposta original do Fundo (Krueger, 2001 e 2002) buscava dar conta, simultaneamente, de dois tipos de problemas. Em primeiro lugar, da pressão política contrária aos mega-pacotes de socorro dos órgãos multilaterais, normalmente sob a liderança do FMI e o apoio do Tesouro dos EUA. Era uma resposta ao argumento do risco moral, pelo qual o modelo de intervenção oficial nas crises dos anos 1990 induziria os investidores privados a ampliarem suas posições ativas para além dos critérios racionais de rentabilidade ajustada ao risco, e ao problema da limitação orçamentária do Fundo ${ }^{22}$. Nessa linha, a Comissão Meltzer (2000) sugeriu uma redução no escopo da atuação financeira das agências multilaterais. Em segundo lugar, do recrudescimento da instabilidade e do enfrentamento de comportamentos oportunistas por parte de investidores privados. Aqui, ao se assumir a existência de assimetrias de informação, comportamentos oportunistas (do tipo free rider) e outras imperfeições do mercado financeiro internacional, o Fundo viu-se diante da necessidade de ir além da sua própria abordagem de reformas que, até então, enfatizava a disseminação das melhores práticas entre os países em desenvolvimento. Implicitamente, assume-se a insuficiência da "primeira geração" de reformas da arquitetura financeira internacional.

Colocou-se, no centro do debate, um tema polêmico, qual seja, o dos conflitos entre credores e devedores na esfera internacional Das alternativas em debate ${ }^{23}$, a via oficial, proposta originalmente por Krueger ${ }^{24}$, tinha um caráter mais institucional e buscava enfrentar os problemas coordenação associados às crises de endividamento. Já a via de mercado propunha soluções descentralizadas, enfatizando os mecanismos contratuais livremente pactuados entre as partes. Nesta via, "reformistas" como Eichengreen $(1999,2002)$ admitiam a introdução de Cláusulas de Ação Coletiva (CACs) para resolver os problemas de coordenação entre os credores, mesmo que os mais puristas seguissem

\footnotetext{
${ }^{21}$ Comportamento considerado racional nos marcos das finanças comportamentais (behavioral finance), que critica a hipótese da eficiência dos mercados financeiros (Shiller, 2003).

${ }^{22}$ Krueger destaca que, ao contrário dos Bancos Centrais que podem emitir moeda de curso forçado, o FMI não cria liquidez. Por isso, necessariamente, havia limitações para o exercício de um emprestador em última instância, nos termos de Bagehot - fornecer, tempestivamente, uma significativa quantidade de recursos a taxas punitivas.

${ }^{23}$ Cunha (2002) detalha os aspectos formais de cada proposta, bem como suas origens econômicas e legais.

${ }^{24}$ A solução apontada aproxima-se do modelo de falência privada das corporações norte-americanas. Tratar-se-ia, portanto, da discussão de um arcabouço capaz de viabilizar processos de "falências soberanas", ou, nos termos de Krueger, de "reestruturação de dívida soberana", ou, ainda, "criar um catalisador que encoraje devedores e credores a unirem-se na reestruturação de dívidas insustentáveis de um modo tempestivo e eficiente". Seguindo a explicação de Krueger (2001) "este catalisador poderia tomar a forma de um arcabouço oferecendo ao país devedor proteção legal contra credores que estejam obstaculizando uma reestruturação necessária, em troca da obrigação para o devedor de negociar de boa fé com seus credores e implementar políticas que assegurem a prevenção do surgimento de problemas semelhantes no futuro."
} 
defendendo a manutenção do status quo em que as renegociações devem se dar de forma livre - bail in (Roubini, 2002). A proposta do Fundo traduzia a tradição dos EUA, de institucionalizar o problema da reestruturação de dívidas. Tal institucionalização não implica, necessariamente, em um maior apelo a soluções judiciais. $\mathrm{Na}$ verdade, estimulam-se acordos "fora das cortes", porém mediados por um embasamento legal capaz de estabilizar a arbitragem entre as partes. Já no plano internacional, os investidores privados dos países credores tendem a ser arredios aos mecanismos de maior institucionalização dos conflitos. A pulverização de interesses e a possibilidade de obtenção de ganhos em negociações privadas, ainda mais quando as estratégias do tipo free rider são consideradas, reduzem o apetite por soluções estatutárias. Não à toa, o setor privado (IIF, 2002) com o apoio do Tesouro dos EUA (Taylor, 2002) passou a contestar fortemente a solução estatutária, defendendo as CACs como second best à livre-negociação. O Fundo perdeu respaldo político ${ }^{25}$ para aprofundar a discussão desse tema e recuou para o estimulo à adoção das CACs (Group of Eight, 2003, IMFC, 2003, Krueger, 2003, 2003b). Em recente encontro do G8, os Ministros das Finanças nem citaram a proposta do Fundo para a operacionalização do $\mathrm{SDRM}^{26}$. Enalteceram-se os avanços no sentido de adoção das CACs, bem como a adoção de "regras de boa conduta" que visem minimizar o risco da emergência de comportamentos oportunistas No encontro conjunto do FMI e Banco Mundial, em abril de 2003, foi destacado o apoio à seqüência no trabalho de supervisão, disseminação de melhores práticas por parte das agências multilaterais. Por outro lado, sepultou-se a "agenda ampliada" associada à discussão do SDRM, optando-se pelos aspectos mais amplamente aceitos da "agenda mínima": “ (o) Comitê, mesmo reconhecendo que não é factível avançar agora rumo ao estabelecimento do SDRM, concorda que o trabalho prossiga em questões levantadas ao longo do seu desenvolvimento que são de relevância geral para a resolução ordenada de crises financeiras. Estas questões incluem considerações sobre as relações entre credores, o aprimoramento da transparência e questões sobre a agregação." (IMFC, 2003:§ 15).

Pode-se perceber aqui uma certa contradição entre o que, nos países centrais e, principalmente, nos EUA, é considerado como sendo as melhores práticas domésticas e o que se está propondo para o "avanço" nas relações entre "credores" e "devedores" no plano internacional. Isso porque, as legislações nacionais de falência surgiram a partir da necessidade de se evitar os aspectos destrutivos das quebras generalizadas de empresas quando da retração do ciclo econômico (Rogoff \& Zettelmeyer, 2002). Funcionavam, junto com as políticas fiscais e monetárias anti-cíclicas (Big Government e o Big Bank, nos termos de Minsky) como elementos atenuadores da instabilidade das economias nacionais. A posição oficial dos EUA, em linha com a visão de Wall Street, considera que o que é bom para as empresas e governos sub-nacionais no território legal do país, ou seja, o seu modelo de legislação de falência, não é bom para o conjunto da coletividade internacional. Por isso a defesa do estabelecimento de acordos contratuais entre as partes, na forma de cláusulas de ação coletiva, modelo que emerge da experiência britânica de enfrentamento de crises de endividamento no setor privado. Da mesma forma que em outros momentos onde emergia a disjuntiva "plena liberdade de ação dos atores locais" versus "equilíbrio no plano das relações internacionais", as pressões políticas atuaram, nesse tema claramente não convencional, no sentido de manter o status quo. Guardadas as devidas proporções, a transformação de uma potencialmente "agenda ampla" em uma efetiva "agenda mínima" de reformas na arquitetura financeira internacional, remete ao espírito dos embates vividos em outros momentos de

\footnotetext{
${ }^{25}$ Isto aparece de forma sutil em recente pronunciamento de Anne Krueger sobre o tema do equacionamento de dívidas: "Enquanto agora nós não temos o apoio de alto nível que seria necessário para tornar exeqüível a adoção do mecanismo proposto (...) $\mathrm{O}$ foco do nosso esforço atual é promover a inclusão de cláusulas de ação coletiva. Nos contratos de dívida e, mais amplamente, encontrar formas de aprimorar arranjos para a reestruturação de dívida soberana dentro do arcabouço legal existente.” (Krueger, 2003b, parágrafos 12 e 13).

26 "Nós reafirmamos nosso compromisso com o fortalecimento de nossas medidas de prevenção e resolução de crises, através do aprimoramento da supervisão do FMI, e a resolução de dívidas insustentáveis de forma mais transparente, ordenada, tempestiva e previsível. Felicitamos a decisão do Brasil, África do Sul, e Uruguai em adotar cláusulas de ação coletiva, seguindo a liderança do México, e encorajamos os países a adotarem CACs em termos que facilitem a reestruturação de dívidas" (Grupo of Eight, 2003:2).
} 
tentativa de ordenamento do mundo das finanças, como no período de gestação do Acordo de Bretton Woods.

\section{Considerações Finais}

Ao longo dos últimos 130 anos, é possível identificar-se diversos ciclos de expansão e contração dos mercados financeiros internacionais. A literatura que enfatiza os aspectos históricos e institucionais, e que busca as regularidades empíricas dos vários momentos de conformação da "globalização financeira", sugere que aos movimentos de integração dos países em desenvolvimento nos circuitos mais dinâmicos de fluxos financeiros, seguem-se episódios de contração na liquidez e de crises financeiras. Cria-se, nas rupturas, a necessidade de um novo ordenamento das bases institucionais que dão suporte ao desenvolvimento dos mercados. Depois da instabilidade do entre guerras, o arranjo cambial centrado do padrão dólar-ouro e as instituições multilaterais criadas com o Acordo de Bretton Woods, formaram a base necessária para a recuperação das economias devastadas pelo conflito bélico, em um ambiente que ficou marcado pelo crescimento da renda, por uma relativa estabilidade política, social e macroeconômica e pelo restabelecimento do comércio internacional em bases multilaterais. Ainda assim, em sua origem o Acordo revelou a existência de uma tensão entre duas posições antagônicas. De um lado, a defesa de criação de uma moeda internacional regulada por um banco central também internacional, em uma "agenda ampla de reformas" arquitetada por Keynes. Buscava-se com isso, ampliar o grau de autonomia para que os governos locais pudessem empreender políticas anti-cíclicas, e distribuir melhor o ônus dos ajustes nos balanços de pagamentos. De outro, a defesa da "agenda mínima", onde o dólar norte-americano como divisa-chave e o FMI como instância de coordenação dos arranjos monetários e cambiais e fonte (extremamente limitada) de liquidez, serviriam para ordenar o macro-ambiente financeiro internacional. $\mathrm{O}$ modelo vencedor preservou o papel hegemônico do país emissor da divisa-chave, apesar do risco, inicialmente potencial, e depois efetivo, do estabelecimento de contradições entre o estabelecimento de políticas econômicas voltadas aos interesses domésticos e a preservação da estabilidade internacional.

Nas três décadas que se seguira à ruptura do Acordo de Bretton Woods, predominou um "nãosistema", onde as taxas câmbio e os preços dos principais ativos financeiros passaram a flutuar livremente em mercados cada vez mais profundos e integrados internacionalmente. Nesse período, houve pelo menos dois ciclos de endividamento e crise das economias periféricas. No episódio mais recente, as crises financeiras da década de 1990 ensejaram a emergência de uma nova rodada de discussões sobre reformas na arquitetura financeira internacional. Mais uma vez, ante o confronto de uma "agenda ampla" e outra "mínima", venceu a segunda. As evidências empíricas predominantes sugerem que a globalização financeira dos anos 1980 e 1990 não foi capaz de promover crescimento e estabilidade nos países em desenvolvimento. Pelo contrário, ampliou-se a volatilidade macroeconômica. Diante desse fato, o foco das reformas da "agenda mínima" tem sido o de fortalecer os "elos frágeis" da corrente global dos mercados, qual sejam, os mercados emergentes. A capacidade das reformas institucionais "focadas" nos emergentes garantir um ambiente mais estável para as finanças internacionais só será testada no futuro, quando de um novo ciclo de afluxo de capitais com ampliação no endividamento das economias em desenvolvimento. Se a experiência histórica serve de bússola para alguma coisa, deve-se no mínimo preservar um espírito de cautela ante à provável emergência de um novo período de excesso de otimismo quanto às virtudes dos mercados financeiros globalizados e desregulamentados. Nesse sentido, talvez fosse mais prudente seguir avançando em linhas como a proposição original do SDRM. Todavia, os limites políticos a propostas não convencionais estão postos e firmes, impedindo, até o presente momento, a consolidação de uma agenda ampliada de reformas. Na margem da "agenda mínima" algumas economias periféricas estão buscando ampliar seus graus de liberdade através de uma crescente cooperação regional na área 
financeira, como no caso asiático ${ }^{27}$. Talvez essa seja uma alternativa possível, diante de interesses consolidados no establishment oficial e privados dos países credores, contrários à criação de bases multilateriais e estatutárias de ordenamento dos conflitos de interesses nos mercados financeiros.

6. Referências Bibliográficas

AGLIETTA, M. (1995) Macroéconomie Financière, Paris: Édition La Découverte, $1^{\mathrm{a}}$ edição.

AKYÜZ, Y., CORNFORD, A. (1999). Capital Flows to Developing Countries and the Reform of the International Financial System. UNCTAD Discussion Paper, n. 143. Genebra: United Nations Conference on Trade and Development - United Nations.

AMADO, A. M. (2003). Minsky e o Ciclo Econômico: uma análise para as economias periféricas. Anais do VIII Encontro de Economia Política, Florianópolis, 17 a 20 de junho.

ANDRADE, J. P., SILVA, M.L.F. (1999). Divergências e Convergências Sobre as Crises Cambiais. In LIMA, G. T, SICSÚ, J., PAULA, L. F. (1999). Macroeconomia Moderna: Keynes e a Economia Contemporânea. Rio de Janeiro: Campus.

ARIYOSHI, A., HABERMEIER, K., LAURENS, B., OTKER-ROBE, I., CANALES-KRILJENKO, J.I., KIRILENKO, A. (2000). Capital Controls: Country Experiences with Their Use and Liberalization. IMF Occasional Paper No. 190. Washington, DC: International Monetary Fund.

AZIZ, J., CARAMAZZA, F., SALGADO, R. (2000). Currency Crises: In Search of Common Elements. IMF Working Paper, WP/00/67. Washington, DC: International Monetary Fund.

BACHA, E. (2002). Do Consenso de Washington ao Dissenso de Cambridge. In BNDES (2002). Desenvolvimento em Debate. Rio de Janeiro: BNDES.

BELluZO, L.G. M., COUTINHO, L (1996). Desenvolvimento e Estabilização Sob Finanças Globalizadas. Economia e Sociedade, $n^{\circ}$ 7. Campinas: Instituto de Economia/Unicamp.

BORDO, M., EICHENGREEN, B., IRWIN, D. (1999). Is Globalization Today Really Different Than Globalization a Hundred Years Ago?. NBER Working Paper 7195. Cambridge, Mass.: National Bureau of Economic Research.

BORDO, M., FLANDREAU, N. (2001). Core, Periphery, Exchange Rate Regimes, and Globalization. NBER Seminar "Globalization in Historical Perspective", may. Cambridge, Mass.: National Bureau of Economic Research.

BORDO, M., EICHENGREEN, B., (2002). Crises Now and Then: What Lessons form the Last Era of Financial Globalization? NBER Working Paper 8716. Cambridge, Mass.: National Bureau os Economic Research.

CALVO, G.. A., MENDONZA, E. G. (1997). Rational Herding Behavior and the Globalization of Securities Markets. Discussion Paper n. 120, Institute of Empirical Macroeconomics, Federal Bank of Minneapolis.

CALVO, G. A. (1998). Balance of Payments Crises in Emerging Markets. NBER Conference on Currency Crises, Cambridge, Mass., february 6 and 7. (mimeo)

\footnotetext{
${ }^{27}$ Através da Iniciativa de Chiang Mai, as economias da ASEAN, Coréia e China, com o apoio do Japão, estão construindo uma rede swaps cambiais, um potencial embrião para a constituição de um Fundo Monetário Asiático. Recentemente, verificou-se uma bemsucedida emissão internacional de um bônus denominado em diversas moedas domésticas, no que se está denominando de Asian Bond Iniciative (Cunha, 2003).
} 
CEPAL (2002). Growth with Stability: financing for development in the new international context. Santiago, Chile: Comissión Económica para America Latina y Caribe.

CHESNAIS, F. (1996). A Mundialização do Capital. São Paulo: Xamã.

CHICK, V. (1988). The Evolution of Monetary System and the Theory of Monetary Policy. London: University College London. (mimeo)

COUNCIL OF FOREIGN RELATIONS TASK FORCE (1999). Safeguarding Prosperity in a Global Financial System: The Future International Financial Architecture. Washigton, DC: Institute for International Economics.

CUNHA, A. M. (2002). Reformas na Arquitetura Financeira Internacional: novidades no front? XXX Encontro Nacional de Economia - ANPEC, Nova Friburgo, dezembro.

CUNHA, A. M. (2003). Iniciativa de Chiang Mai: Integração Financeira e Monetária no Pacífico Asiático. Anais do VIII Encontro Nacional de Economia Política, Florianópolis, junho.

CUNHA, A. M., PRATES, D. (2003). Instabilidade e Crises: os avanços teóricos e os limites políticos para os países periféricos. In FERRAZ, J.C., CROCCO, M., ELIAS, L.M. (2003). Liberalização Econômica e Desenvolvimento. São Paulo: Editora Futura.

DAVIDSON, P. (1992). Reforming the World's Money. Journal of Post Keynesian Economics, v. 15, n.2, p. 153-79.

DEMIRGÜÇ-KUNT, A., DETRAGIACHE, E. (1998). Financial Liberalization and Financial Fragility. IMF Working Paper, 98/83, june. Washington, DC: International Monetary Fund.

EATWELL, J., TAYLOR, L. (1998). International Capital Markets and the Future of Economic Policy. CEPA Working Paper Series III, n.9.

EDISON, H., KLEIN, M., RICCI, L., SLOK, T. (2002). Capital Account Liberalization and Economic Performance: a review of the literature. IMF Working Paper 02/120. Washington, DC: International Monetary Fund.

EDWARDS, S. (1995). Capital Controls, Exchange Rate and Monetary Policy in the World Economy. MA: Cambridge University Press.

EDWARDS, S. (2002). Crescimento Econômico na América Latina: desafios para uma nova era. In BNDES (2002). Desenvolvimento em Debate. Rio de Janeiro: BNDES.

EICHENGREEN, B. (1996). Globalizing Capital: a history of the international monetary system. Princeton: Princeton University Press.

EICHENGREEN, B. (1999).Toward a New International Financial Architecture: A Practical PostAsia Agenda. Institute for International Economics.

FENDT, R., LINS, M.A.T. (2002, orgs). Arquitetura Assimétrica: o espaço dos países emergentes e o sistema financeiro internacional. São Paulo: Fundação Konder Adenauer.

FERRARI FILHO, F. (1999). A Moeda Internacional na Economia de Keynes. In LIMA, G. T, SICSÚ, J., PAULA, L. F. (1999). Macroeconomia Moderna: Keynes e a Economia Contemporânea. Rio de Janeiro: Campus.

FURMAN, J., STIGLITZ, J.E. (1998). Economic Crises: Evidence and Insights from East Asia. Brookings Papers on Economic Activity, n.2, p. 1-135. Washington: Brookings Institution. 
GOLDSTEIN, M. (2001). An Evaluation on Proposals to Reform on International Financial Architecture. NBER Conference on Management of Currency Crises.

GREENSPAN, A. (1997). Remarks by Chairman Alan Greenspan at the Economic Club of New York, NY (december, 2). (mimeo)

GRIFFITH-JONES, S. (1995). Globalización de los Mercados Financieros y el Impacto de los Flujos hacia los Países en Desarrollo: Nuevos Desafíos para la Regulación. Pensamiento Iberoamericano n. 27 , Madrid.

FISCHER, S. (1999). On the Need of International Lender of Last Resort. Washington: International Monetary Fund.

FISCHER, S. (2001). Asia and the IMF. Washington, DC: International Monetary Fund.

GARTEN, J. (1998). In This Economic Chaos, a Global Central Bank Can Help. International Herald Tribune, september, 25th, p.8.

GROUP OF SEVEN FINANCE MINISTERS (2000). Strengthening the International Financial Architecture. Report to the Heads of State and Government, Fukuoka, july, $8^{\text {th }}$.

GROUP OF EIGHT (2003). Finance Ministers' Statement, Deauville, May $17^{\text {th }}$.

IIF (2002). Sovereign Debt Restructuring. Washington, DC: Institute of International Finance.

IMF (1998). World Economic Outlook, may. Washington: International Monetary Fund.

Washington DC: International Monetary Fund .

IMF (2000). International Financial Architecture: An Update on Bank Activities. Development Committee, DC/2000-20. Washington DC: International Monetary Fund.

IMF (2001). World Economic Outlook, october. Washington: International Monetary Fund.

IMFC (2003). Communiqué of the International Monetary and Financial Committee, Board of Governors of the International Monetary Fund, April $12^{\text {th }}$.

KAMINSKY, G., LIZONDO, S., REINHART, C. (1998). Leading Indicators of Currency Crisis. Washington DC: IMF (mimeo).

KEYNES, J. M. (1943). The International Clearing Union. In HARRIS, S.E. (1950, org.). The New Economics: Keynes Influence on Theory and Public Policies. New York: Alfred A. Knopf. Reproduzido em português em: SZMRECSÁNYI, T. (1978). John Maynard Keynes: economia. São Paulo: Ática.

KEYNES, J. M. (1944). The International Monetary Fund. In HARRIS, S.E. (1950, org.). The New Economics: Keynes Influence on Theory and Public Policies. New York: Alfred A. Knopf. Reproduzido em português em: SZMRECSÁNYI, T. (1978). John Maynard Keynes: economia. São Paulo: Ática.

KREGEL, J. A (1998). Yes, "It" Did Happen Again - A Minsky Crisis Happened in Asia. Presented at the Eighth Annual Hyman P. Minsky Conference on Financial Structure, april 23-24. Working Paper n. 234, The Jeromy Levy Economic Institute.

KRUEGER, A. O. (2001). International Financial Architecture for 2002: A New Approach to Sovereign Debt Restructuring. Speech at the National Economists' Club Annual Members' Dinner American Enterprise Institute, Washington DC, november 26. 
KRUEGER, A. O. (2002). A New Approach to Sovereign Debt Restructuring. Washington: International Monetary Fund.

KRUEGER, A. O. (2003). Remarks at the International Monetary Seminar, Banque de France, may 13.

KRUEGER, A. O. (2003b). The Need to Improve the Resolution of Financial Crises: An Emerging Consensus? Harvard University Business School's Finance Club, Boston, March 27.

KRUEGER, A. O. (2003c). Detecting and Preventing Financial Crises-Recent IMF Approaches. Speech at the Bretton Woods Committee Annual Meeting U.S. State Department, june.

KRUGMAN, P. (1997). Currency Crises. (mimeo).

MALKIEL, B. G. (2003). The Efficient Market Hypothesis and Its Critics. Journal of Economic Perspectives, v. 17, n.1, p. 83-104.

MELTZER, A. H. (2000 - Chairman). Report of the International Financial Institution Advisory Comission. Washington, DC: International Financial Institution Advisory Comission.

MILlER, M. (2002). Sovereign Debt Restructuring: New Articles, New Conctracts - or No Change? International Economics Policy Briefs, 02/3, april. Washington, DC: Institute of International Economics.

MINSKY, H. P. (1986). Stabilizing and Unstable Economy. New Haven: Yale University Press.

MINSKY, H. P. (1991). The Financial Instability Hypothesis: a Clarification. . In FELDSTEIN, Martin (1991). The Risk of Economic Crisis. Chicago: The University of Chicago Press.

MISHKIN, F. S. (1992). Anatomy of a Financial Crisis. Journal of Evolutionary Economics, n.2, p.115-130.

OCAMPO, J.A (2003). Latin America's Growth Frustrations: the macro and mesoeconomic links. Seminar on Management of Volatility, Liberalization and Growth in Emerging Markets. Santiago, Chile: Comissión Económica para America Latina y Caribe.

PAULA, L.F., ALVES JR., A.J. (2000). External Financial Fragility and the 1998-1999 Brazilian Currency Crises. Journal of Post Keynesian Economics, v. 22, n.4.

PRATES, D. M. (2003). As Crises Financeiras dos Países Periféricos nos Anos 90: Uma Análise Crítica do Pensamento Convencional. Campinas: Instituto de Economia (Tese de Doutorado não publicada).

PRASAD, E., ROGOFF, K., WEI, S., KOSE, M.A (2003). Effects of Financial Globalization on Developing Countries: Some Empirical Evidence.

RADALET, S., SACHS, J. D. (1998). The East Asian Financial Crisis: Diagnosis, Remedies, Prospects. Brookings Papers on Economic Activity, n.1. Washington, DC: Brookings Institution.

RODRIK, D. (1998). Who Needs Capital-Account Convertibility?. (http://ksghome.harvard.edu/ .drodrik.academic.ksg/papers.html)

RODRIK, D. (2001). The Developing Countries Hazardous Obsession with Global Integration. (http://ksghome.harvard.edu/ .drodrik.academic.ksg/papers.html)

RODRIK, D. (2002). Depois do Neoliberalismo, o Quê? In BNDES (2002). Desenvolvimento em Debate. Rio de Janeiro: BNDES. 
ROGOFF, Kenneth (1999). International Institutions for Reducing Global Financial Instability. NBER Working Paper, 7265. Cambridge, Massachusetts: National Bureau of Economic Research.

ROGOFF, K. (2002). Rethinking Capital Controls: When Should We Keep an Open Mind? Finance and Development, v. 39, n. 4. Washington, DC: IMF.

ROGOFF, K., ZETTELMEYER, J. (2002). Early Ideas on Sovereign Bankruptcy: A Survey. IMF Working Paper 02/57, march. Washington: International Monetary Fund.

ROUBINI, N. (2002). Do We Need a New International Bankruptcy Regime? Comments on Bulow, Sachs and White. Brookings Panel on Economic Activity "Symposium: A Bankruptcy Court for Sovereign Debt", april, 5, Washington, DC.

SACHS, J. D. (1995). Do We Need a International Lend of Last Resort? Frank D. Graham Lecture at Princeton University, april, 20 (mimeo).

SCHNEIDER, M., TORNELL, A. (1999). Lending Booms and Asset Price Inflation. (mimeo)

SCHNEIDER, M., TORNELL, A. (2000). Balance Sheet Effects, Bailout Guarantees and Financial Crises. NBER Working Paper 8060, december. Cambridge, MA: National Bureau of Economic Research.

SHILLER, R. J. (2003). From Efficient Markets Theory to Behavioral Finance. Journal of Economic Perspectives, v. 17, n.1, p. 83-104.

SOROS, George (1998). The Crises of Global Capitalism. New York: Public Affairs.

StiGlitZ, J. E. (2002). A Globalização e Seus Malefícios. São Paulo: Futura.

SUMMERS, L. (1999). The Right King of IMF for a Stable Global Financial System. Speech to the London School of Business, december, $14^{\text {th }}$.

TAYlOR, J. (2002). Sovereign Debt Restructuring: A U.S. Perspective. Disponível no site: http://www.treas.gov/press/releases/po1016.htm

TRIFFIN, R. (1960). Gold and the Dollar Crisis. New Haven: Yale University Press.

TRUMAN, E. M. (2001). Perspectives on External Financial Crises. Washington, DC: Institute for International Economics. Disponível no site: http://www.iie.com/papers/truman1201.htm.

UNCTAD (2001). Trade and Development Report, 2001. Genebra: United Nations Conference on Trade and Development - United Nations.

WORLD BANK (2000). Global Development Finance, 2000. Washington, DC: World Bank.

WORLD BANK (2001). Globalization, Growth and Poverty. Washington: World Bank.

YOSHITOMI, M., SHIRAI, S. (1999). Capital-Account Crisis and Credit Contraction: The New Nature of the Crisis Requires New Policy Responses. ADB Working Paper, n.2 Tokyo: Asian Development Bank Institute. 